\title{
Assessment of the potential of a boron-fructose additive in counteracting the toxic effect of Fusarium mycotoxins
}

\author{
Ionelia Taranu $^{1 *}$, Daniela E. Marin ${ }^{1}$, Gina Manda ${ }^{2}$, Monica Motiu ${ }^{1}$, Ionela Neagoe ${ }^{2}$, Cristina Tabuc ${ }^{1}$, \\ Mariana Stancu ${ }^{1}$ and Margareta Olteanu ${ }^{1}$ \\ ${ }^{1}$ INCDBNA, National Institute of Research and Development for Biology and Animal Nutrition, 1, Calea Bucuresti, 077015 \\ Balotesti, Romania \\ ${ }^{2}$ National Institute of Pathology 'Victor Babes', Bucharest, Romania
}

(Received 27 July 2010 - Revised 18 November 2010 - Accepted 18 January 2011 - First published online 14 March 2011)

\begin{abstract}
Trichotecenes are mycotoxins produced by Fusarium sp., which may contaminate animal feeds and human food. A feeding trial was conducted to evaluate the effect of a fusarotoxin-contaminated diet, and to explore the counteracting potential of a calcium fructoborate $(\mathrm{CFrB})$ additive on performance, typical health biochemistry parameters and immune response in weaned pigs. A naturally contaminated maize, containing low doses of deoxynivalenol, zearalenone, fumonisins and T-2/HT-2 toxins (1790, 20, 0.6 and 90 parts per billion), was included in a maize-soyabean meal diet, and given ad libitum to eight weaned piglets (two groups: four pigs/group) for a period of $24 \mathrm{~d}$. CFrB was administered to one of the contaminated groups and to another four piglets as a daily supplement, following the manufacturer's recommendation. A decrease in performance was observed in contaminated animals at this concentration of feed toxins, which was ameliorated by the dietary CFrB supplementation. Fusarium toxins also altered the pig immune response by increasing $(P<0 \cdot 05)$ the ex vivo peripheral blood mononuclear cell proliferation ( $111.7 \%$ in comparison with control), the respiratory burst of porcine granulocytes ( $15 \cdot 4 \%$ for responsive cells $v .5 .1 \%$ for unstimulated cells and $70.95 v .22 .65 \%$ for stimulated cells, respectively), the percentage of peripheral T, $\mathrm{CD}^{+}, \mathrm{CD}^{+} \mathrm{CD}^{+}$and $\mathrm{CD}^{+}{ }^{+} \mathrm{CD}^{+}$subsets and the synthesis of IL-1 $\beta$, TNF- $\alpha$ and IL-8 $(123 \cdot 8,217 \cdot 1$ and $255 \cdot 1 \%$, respectively). The diet containing the $\mathrm{CFrB}$ additive reduced these exacerbated cellular immune responses induced by Fusarium toxins. However, consumption of CFrB did not counteract the effect of mycotoxins on biochemistry parameters, and increased plasma IgM and IgG of contaminated pigs.
\end{abstract}

Key words: Pigs: Fusarium toxins: Decontaminating agents: Immune response

Mycotoxins are some of the most frequent natural contaminants of cereals. A list of mycotoxins which are of concern for the safety of animal feed in the European Union (EU32/ 2003) has been already published. For instance, Fusarium culmorum and Fusarium graminearum are ubiquitous species of the Fusarium genus that can release a large array of mycotoxins: fumonisins, toxin T-2, toxin HT-2, ochratoxin A, deoxynivalenol (DON), zearalenone (ZEA), etc. ${ }^{(1)}$. DON and ZEA have a particular importance with their common co-occurrence, high frequency (particularly in the temperate climate) and very high toxic effect. In feed, high doses of DON and ZEA (higher than 3 and 1 parts per million (ppm), respectively) provoked effects such as diarrhoea, vomiting, feed refusal, reduced weight, reproductive disorders and ultimately death. Chronic low-dose toxicity is characterised by anorexia, reduced weight gain, nutrient malabsorption, neuroendocrine changes and immunological effects ${ }^{(2,3)}$.
Despite the intense efforts of prevention, mycotoxin contamination of feed occurs in the field ${ }^{(4)}$. Therefore, various detoxification strategies have been developed over time. These procedures/methods can be grouped into three categories: physical, chemical and biological ${ }^{(5)}$. Dietary strategies, including biological mitigating agents, are some of the most recent approaches in reducing the adverse effects of mycotoxins. The extraordinary development in this area has been lately helped by recent advances in molecular biology, genetic engineering and microbial genomics ${ }^{(6-8)}$. A large number of studies have investigated the ability of several binding dietary agents (activated carbons, hydrated sodium calcium aluminosilicate, bentonite and zeolites) in reducing the negative effects of mycotoxins in feed ${ }^{(9-11)}$. While this research demonstrated good results against aflatoxins (especially aluminosilicate), their efficacy to bind other toxins, or more than one mycotoxins in case of co-contamination,

Abbreviations: CFrB, calcium fructoborate; DON, deoxynivalenol; PBMC, porcine peripheral blood mononuclear cell; ppm, parts per million; ZEA, zearalenone. 
must be confirmed. Some of the available mycotoxin binders failed in sequestering the in vitro/in vivo Fusarium mycotoxins in pigs, for example ${ }^{(12)}$. Recently, there has been an increasing interest in the use of bacteria, yeast and fungi as binders to successfully reduce the toxic effect of mycotoxins ${ }^{(13)}$. It has also been shown that substances which do not interact with mycotoxins, i.e. several plant extracts and spice oils, antioxidant compounds (Se, vitamins, provitamins) and feed/food components (phenolic compounds, coumarin, chlorophyll and its derivatives, fructose, aspartame), are efficient in counteracting the toxic effect of contaminants, but, again, available data are provided from the in vitro studies, and especially focus on aflatoxin $\mathrm{B}_{1}^{(14)}$. It is clear that much more research must be conducted to identify, especially in vivo, the detoxification ability of the aforementioned control agents, their mode of action, and their economical and technical feasibility.

Therefore, the objectives of the present study were to evaluate in vivo the ability of a nutritional complex compound (a protein concentrate additive, enriched in calcium fructoborate (CFrB), a natural ester of boric acid with fructose) in counteracting the toxic effect of feeding a diet containing naturally contaminated maize with low levels of Fusarium toxins (DON as the major contaminant and ZEA, fumonisin and HT-2 toxin as the minor components) in starter pigs. As a great consumer of cereals, the pig is one of a broad range of farm animals frequently exposed to mycotoxins. It is also considered one of the most susceptible mammalian species to mycotoxins, and other contaminants, especially during the weaning period, in which changes in nutrition and regrouping are significant and stressing ${ }^{(15)}$. Intake of mycotoxin-contaminated feed in this period could lead to decreases in animal growth performance and reproduction, and an increase in susceptibility to infectious diseases. In the present study, the effect of daily low doses of Fusarium mycotoxins and of an organic additive on production parameters, organ weights, plasma biochemistry and the immune response of peripheral blood cells was investigated. We hypothesise that the use of nutritional complex compounds with polyvalent properties might be promising alternatives in reducing mycotoxin effects.

\section{Materials and methods}

\section{Experimental animals and diets}

A total of sixteen cross-bred starter piglets, with an average body weight of 11.00 (SEM 0.58 ) kg, were identified by ear tags and housed in floored indoor pens. Piglets were divided into four experimental groups (four piglets/group), and were randomly assigned to one of the four treatments: $\mathrm{M}-\mathrm{CFrB}-$ (diet without mycotoxin and without $\mathrm{CFrB}$ additive, control); $\mathrm{M}-\mathrm{CFrB}+$ (diet without mycotoxin, with $\mathrm{CFrB}$ additive); $\mathrm{M}+\mathrm{CFrB}-$ (mycotoxin-contaminated diet without $\mathrm{CFrB}$ additive); $\mathrm{M}+\mathrm{CFrB}+$ (mycotoxin-contaminated diet with CFrB additive) for $24 \mathrm{~d}$. The control diet was formulated to meet all nutritional requirements of $8-30 \mathrm{~kg}$ starter pigs (National Research Council, 1988), with a total maize content of $53.31 \mathrm{~g} / \mathrm{kg}$ (Table 1 ). The mycotoxin-contaminated diet was prepared by replacing 'uncontaminated' control maize with Fusarium mycotoxin-contaminated maize. The contaminated diet contained 1.79 (SEM 0.56) mg Fusarium toxins/kg compound feed, whereas the control diet contained 0.427 (SEM 0.15) mg Fusarium toxins/kg compound feed, which was considered negligible taking into consideration the literature data and EC recommendation 576/2006 ${ }^{(16)}$.

In order to test the capacity of a mitigating additive in reducing the possible negative effects of a mycotoxincontaminated diet, a protein concentrate additive enriched in CFrB was added daily in the contaminated diet of animals according to the manufacturer's instructions (1.65 g/pig). CFrB (FruiteX B ${ }^{\circledR}$ ) was purchased from the FutureCeuticals Company (San Diego, CA, USA) - synthetic product (Miljkovic, US Patent 5,962,049 (1998)), and was identified as Ca $\left[\left(\mathrm{C}_{6} \mathrm{H}_{10} \mathrm{O}_{6}\right)_{2} \mathrm{~B}\right]_{2} \cdot 4 \mathrm{H}_{2} \mathrm{O}$, an ester of boric acid with fructose similar to the natural forms of boron found in edible plants ${ }^{(17)}$. Feed samples were taken at the beginning of the experiment, and were analysed for Fusarium mycotoxins and nutrient content; DM, crude protein, fat, crude fibre and ash were estimated according to the International Standards Organisation methods ${ }^{(18-22)}$ (Table 1). The respective treatments were administered for $24 \mathrm{~d}$. At the end of the experiment, pigs were weighed individually, and cumulative feed consumption was measured for each pen. In order to study the effect of

Table 1. Composition of experimental diets (\%)

\begin{tabular}{|c|c|c|}
\hline Ingredients & Control diet & Contaminated diet \\
\hline Wheat meal & $15 \cdot 00$ & $15 \cdot 00$ \\
\hline Maize meal & $53 \cdot 31$ & 0.00 \\
\hline Contaminated maize meal & 0.00 & $53 \cdot 31$ \\
\hline Soyabean meal & 3.00 & 3.00 \\
\hline Sunflower meal & 8.00 & 8.00 \\
\hline Powder milk & 5.00 & $5 \cdot 00$ \\
\hline Gluten & $2 \cdot 00$ & 2.00 \\
\hline Full-fat soyabean & 9.00 & 9.00 \\
\hline Salt & 0.20 & 0.20 \\
\hline Monocalcium phosphate & 1.30 & 1.30 \\
\hline Feed-grade limestone & 1.60 & 1.60 \\
\hline Methionine premix & $0 \cdot 10$ & $0 \cdot 10$ \\
\hline Lysine premix & 0.40 & 0.40 \\
\hline Choline premix & 0.09 & 0.09 \\
\hline Vitamin-mineral premix ${ }^{*}$ & 1.00 & 1.00 \\
\hline \multicolumn{3}{|l|}{ Nutrient content } \\
\hline \multicolumn{3}{|l|}{ Analysed value (\%) } \\
\hline DM & 89.89 & 89.89 \\
\hline Crude protein & $16 \cdot 64$ & $16 \cdot 64$ \\
\hline Crude fat & $3 \cdot 11$ & $3 \cdot 11$ \\
\hline Crude fibre & 4.35 & 4.35 \\
\hline Ash & 5.06 & 5.06 \\
\hline ME† (kJ/kg) & 13346.96 & 13346.96 \\
\hline \multicolumn{3}{|l|}{ Mycotoxins $(\mu \mathrm{g} / \mathrm{kg})$} \\
\hline DON & 427 & 1790 \\
\hline ZEA & 10 & 20 \\
\hline FB & 0.3 & 0.6 \\
\hline T-2/HT-2 & 50 & 90 \\
\hline
\end{tabular}

$\mathrm{ME}$, metabolisable energy; DON, deoxynivalenol; ZEA, zearalenone; FB, fumonisin. * Vitamin-mineral premix/kg diet: 0-24 d: $10000 \mathrm{IU}$ vitamin A; $2000 \mathrm{IU}$ vitamin D; $30 \mathrm{IU}$ vitamin $\mathrm{E} ; 2 \mathrm{mg}$ vitamin $\mathrm{K} ; 1.96 \mathrm{mg}$ vitamin $\mathrm{B}_{1} ; 3.84 \mathrm{mg}$ vitamin $\mathrm{B}_{2}$; $14.85 \mathrm{mg}$ pantothenic acid; $19.2 \mathrm{mg}$ nicotinic acid; $2.94 \mathrm{mg}$ vitamin $\mathrm{B}_{6} ; 0.98 \mathrm{mg}$ folic acid; $0.03 \mathrm{mg}$ vitamin $\mathrm{B}_{12} ; 0.06 \mathrm{mg}$ biotin; $24.5 \mathrm{mg}$ vitamin $\mathrm{C} ; 40.3 \mathrm{mg} \mathrm{Mn}$; $100 \mathrm{mg} \mathrm{Fe} ; 100 \mathrm{mg} \mathrm{Cu} ; 100 \mathrm{mg} \mathrm{Zn;0.38} \mathrm{mg} \mathrm{I;} 0.23 \mathrm{mg} \mathrm{Se}$. † Calculated. 
various treatments on plasma biochemistry, and the innate and acquired immune response, blood samples were aseptically collected by jugular venepuncture from all animals (heparinised Vacutainer tubes; Vacutest ${ }^{\circledR}$, Arzergrande, Italy). Liver samples were taken after animals were slaughtered, and stored at $-80^{\circ} \mathrm{C}$ until analysed.

Animals were cared for in accordance with the Romanian Law 206/2004 for handling and protection of animals used for experimental purposes. The study protocol was approved by the Ethical Committee of the National Research-Development Institute for Animal Nutrition and Biology, Balotesti, Romania.

\section{Analysis of mycotoxins}

The content of DON in the feed was analysed by HPLC, with UV detection after clean-up with an immune-affinity column, and a detection limit of $0.03 \mathrm{mg} / \mathrm{kg}$ (Table 1). ZEA, fumonisin and T-2/HT-2 toxins were analysed by ELISA using ELISA kits Veratox (Neogen, Lansing, MI, USA) with detection limits of 10, 50 and $25 \mathrm{ppb}$, respectively (Table 1). Ochratoxin A toxin, also analysed by ELISA, was detected in negligible concentration.

\section{Plasma biochemical parameters}

Plasma concentrations of $\mathrm{Na}, \mathrm{K}, \mathrm{Cl}, \mathrm{Ca}, \mathrm{P}, \mathrm{Mg}$, total protein, urea, glucose, bilirubin, and concentrations of alkaline phosphatase, glutamate pyruvate transaminase, glutamate oxaloacetate transaminase were determined on a BS-130 Chemistry analyser (Bio-Medical Electronics Company Limited, Shenzhen, China).

\section{Plasma total Ig subsets (IgG, IgA, IgM)}

Total concentration of Ig subsets was measured by ELISA (Bethyl, Medist, Montgomery, TX, USA) after plasma dilution: 1:4000 (IgA), 1:60000 (IgG) and 1:6000 (IgM), as reported previously ${ }^{(23)}$, and according to the manufacturer's instructions. Absorbance was read at $450 \mathrm{~nm}$ using a microplate reader (Tecan Sunrise, Salzburg, Austria).

\section{Isolation of pig porcine peripheral blood mononuclear cells}

The effect of Fusarium toxins on cellular viability, cell proliferation and T-lymphocyte phenotypes was studied on porcine peripheral blood mononuclear cells (PBMC). Blood collected from all animals was mixed with an equal volume of Dulbecco's PBS (Sigma-Aldrich Chemical Company, Steinheim, Germany), then laid over Ficoll-Hypaque (1.077; Sigma-Aldrich Chemical Company) and centrifuged at 2700 pm, $20 \mathrm{~min}$ at room temperature. PBMC were collected, washed twice in PBS and resuspended in RPMI-1640 (SigmaAldrich Chemical Company), supplemented with 2 mm-glutamine, penicillin $(100 \mathrm{U} / \mathrm{ml})$, streptomycin $(50 \mu \mathrm{g} / \mathrm{ml})$ and $10 \%$ fetal calf serum (Sigma-Aldrich Chemical Company). Cells were counted and viability was assessed using trypan blue (Sigma-Aldrich Chemical Company).

\section{Porcine peripheral blood mononuclear cell proliferation}

The ability of isolated and mitogen-activated PBMC to proliferate ex vivo was measured by the $\left[\right.$ methyl $\left.{ }^{3} \mathrm{H}\right]$ thymidine proliferation assay. PBMC $\left(1 \times 10^{6}\right.$ cells $\left./ \mathrm{ml}\right)$, stimulated or unstimulated with concanavalin A $(10 \mu \mathrm{g} / \mathrm{ml})$ (Type IV; Sigma-Aldrich Chemical Company), were cultured for $72 \mathrm{~h}$ at $37^{\circ} \mathrm{C}$ and $5 \% \mathrm{CO}_{2}$ in ninety-six-well flat-bottomed tissue culture plates (NUNC, Langelnselbold, Germany). For the last $18 \mathrm{~h}$ of cultivation, cells were labelled with $1 \mu \mathrm{Ci} /$ well of [methyl- ${ }^{3} \mathrm{H}$ ] thymidine, and then harvested through glass-fibre filters (Skatron, Sterling, London, UK). Incorporation of [methyl- ${ }^{3} \mathrm{H}$ ]thymidine was measured with a Canberra-Packard Beta Counter (PerkinElmer Life and Analytical Science, Downers Grove, IL, USA), and the results were expressed as counts/min.

\section{Immune phenotyping of lymphocytes}

The percentage of peripheral T-lymphocyte subsets $\mathrm{CD}^{+} \mathrm{CD}^{+}$and $\mathrm{CD}^{+} \mathrm{CD}^{+}$was assessed by flow cytometry. Antibodies were purchased from Becton Dickinson Pharmingen (San Diego, CA, USA). Briefly, $100 \mu$ l of blood harvested in EDTA-coated vacutainers (Vacutest ${ }^{\circledR}$ ) were incubated for $20 \mathrm{~min}$ at room temperature, in the dark, with $0.6 \mu \mathrm{g}(1.2 \mu \mathrm{l})$ of fluorescein isothiocyanate-conjugated mouse anti-pig CD3 $\varepsilon$ monoclonal antibody (clone BB23-8E6-8C9), and $0.5 \mu \mathrm{g}(2.5 \mu \mathrm{l})$ of $R$-phycoerythrin-conjugated mouse anti-pig CD4a monoclonal antibody (clone $74-12-4)$ or $0.5 \mu \mathrm{g}(2.5 \mu \mathrm{l})$ of R-PE-conjugated mouse anti-pig CD8a monoclonal antibody (clone 76-2-11). Fluorescein isothiocyanate-conjugated mouse IgG2ak and R-PE-conjugated mouse IgG2bк were used as isotype controls (clones G155-178 and 27-35). Thereafter, samples were treated for $15 \mathrm{~min}$ with Cell Lyses (BD Biosciences, Heidelberg, Germany) for the removal of erythrocytes. After two washes with $2 \mathrm{ml}$ Cell Wash (Becton Dickinson), cells were finally fixed with $400 \mu$ l Cell Fix (Becton Dickinson), and analysed by flow cytometry using a FACSCanto flow cytometer (Becton Dickinson, Franklin Lakes, NJ, USA) and CellQuest software (Becton Dickinson). At least 10000 events were analysed.

\section{Respiratory burst of granulocytes}

The intracellular production of $\mathrm{H}_{2} \mathrm{O}_{2}$ by peripheral granulocytes was performed by flow cytometry in whole blood using the fluorogenic substrate dihydrorhodamine 123 (BurstTest kit; ORPEGEN Pharma, Heidelberg, Germany). Briefly, ice-cold heparinised blood $(100 \mu \mathrm{l})$ was activated with unlabelled opsonised Escherichia coli for $10 \mathrm{~min}$ at $37^{\circ} \mathrm{C}$. Dihydrorhodamine 123 was then added, and incubation was continued for another $10 \mathrm{~min}$ at $37^{\circ} \mathrm{C}$. Erythrocytes were lysed and fixed for $20 \mathrm{~min}$ at room temperature. Samples were washed twice with washing solution by centrifugation ( $5 \mathrm{~min}, 1200 \mathrm{rpm}, 4^{\circ} \mathrm{C}$ ), and the supernatant was discarded. Finally, $200 \mu \mathrm{l}$ of propidium iodide (DNA-staining solution) were added while samples were kept on ice, in a dark place. Cell analysis was done by flow cytometry using a 
FACSCanto flow cytometer (Becton Dickinson) and CellQuest software (Becton Dickinson). At least 10000 events were analysed. By manual gating, we first selected the population of granulocytes from a forward-scatter $v$. side-scatter plot. Then, we selected single cells and excluded aggregation artifacts, as defined by propidium iodide incorporation. Finally, flow-cytometry data were expressed as the percentage of responsive cells under basal conditions or to a particular ex vivo stimulus, meaning the percentage of cells with fluorescence intensity above a defined threshold (M2). The mean intensity of the cellular response was calculated as the geometrical mean of the fluorescence channel.

\section{Measurement of cytokine production}

Samples of liver were weighed and homogenised in phosphate buffer containing $1 \%$ igepal, $0.5 \%$ sodium deoxycholate, $0 \cdot 1 \%$ SDS, and complete (EDTA-free) protease inhibitor cocktail tablets. The homogenates were kept $30 \mathrm{~min}$ on ice, and then centrifuged at $10000 \mathrm{~g}$ at $4^{\circ} \mathrm{C}$ for $10 \mathrm{~min}$. TNF- $\alpha$, IL-1 $\beta$ and IL- 8 concentrations in the supernatants were determined by ELISA, using commercially available kits (R\&D Systems, Minneapolis, MN, USA), according to the manufacturer's instructions. Optical densities were measured on an ELISA reader (Tecan Sun Rise) at a wavelength of $450 \mathrm{~nm}$. Dilutions of recombinant swine TNF- $\alpha$, IL- $1 \beta$ and IL-8 were used as standards, and data were analysed against the linear portion of the generated standard curve. Results are expressed as pg cytokine/ml supernatant.

\section{Statistical analyses}

ANOVA tests were used to analyse the differences in terms of weight, plasma biochemistry parameters, cell proliferation, Ig synthesis and so on, between the $\mathrm{M}-\mathrm{CFrB}-, \mathrm{M}-\mathrm{CFrB}+$, $\mathrm{M}+\mathrm{CFrB}-$ and $\mathrm{M}+\mathrm{CFrB}+$ groups. $P$ values of 0.05 were considered significant.

\section{Results}

\section{Animal performance}

We first investigated the effect of dietary treatment on clinical signs and animal performance. Piglets were fed with control or Fusarium mycotoxin-contaminated diets (1.79 ppm) and a mitigating additive, $\mathrm{CFrB}$, for a period of $24 \mathrm{~d}$. Control animals as well as piglets fed with the mycotoxin-contaminated diet appeared clinically normal during the whole experiment, and no deaths resulted from the intoxication; but at the end of the feeding period, the performance of the contaminated piglets was lower than those in the control and CFrB groups (Fig. 1). Indeed, Fusarium mycotoxin significantly retarded average daily weight gain, from 0.458 (SEM 0.12) $\mathrm{kg}$ for the control animals to $0 \cdot 292$ (SEM $0 \cdot 17$ ) kg for the Fusarium mycotoxin-treated animals. The gain:feed ratio was also reduced in pigs fed with contaminated diets (2.312 (SEM 0.67) for the control v. 3.029 (SEM 1.43) for the contaminated pigs). However, this reduction was not significant, and the effect was alleviated by the supplementation of feed with the mitigating additive (0.431 (SEM 0.11) and 2.912 (SEM 1.01) kg, respectively).

\section{Organ weights}

The weight of the internal organs was also measured in animals from the different diet groups. The absolute weights of liver, kidney, spleen and lung were not influenced by the diet supplemented with CFrB alone, but were lower in pigs that received the mycotoxin-contaminated diet compared with control, without significant differences between mean values (Table 2). However, the supplementation of the contaminated diets with the CFrB additive restored the decreased organ weights caused by mycotoxins, with a significant difference for lung weight $(\mathrm{M}+\mathrm{CFrB}+v \cdot \mathrm{M}+\mathrm{CFrB}-, P<0 \cdot 05)$. The expression of the internal organ weight assessed as the ratio of organ weight:metabolic body weight $\left(\mathrm{BW}^{0.75}\right)$ was still reduced in pigs fed with the $\mathrm{M}+\mathrm{CFrB}-$ diet and ameliorated in pigs fed with the $\mathrm{M}+\mathrm{CFrB}+\operatorname{diet}$ (data not shown).

\section{Plasma biochemistry}

Biochemistry analysis was also performed in the plasma of animals receiving the different diet treatments. Supplementation of the diet with $\mathrm{CFrB}$ additive resulted in a significant increase in $\mathrm{Na}(P<0.05)$ concentration, the other plasma biochemistry parameters being less influenced, and registered either a non-significant increase $(\mathrm{P}$, aspartate aminotransferase and alanine aminotransferase enzymes) or decrease $(\mathrm{Cl}, \mathrm{Ca}$,

\begin{tabular}{cc|cc|c}
\multicolumn{4}{c}{ AWG (kg) and feed efficiency (kg:kg) } \\
\hline \multicolumn{3}{c}{ AWG $(\mathrm{kg})$} & \multicolumn{2}{c}{ Gain:feed } \\
\hline Groups & Mean & SEM & Mean & SEM \\
\hline M-CFrB- & 0.458 & 0.12 & 2.312 & 0.67 \\
M-CFrB+ & 0.511 & 0.05 & 1.803 & 0.12 \\
M+CFrB- & 0.292 & 0.17 & 3.029 & 1.43 \\
M+CFrB- & 0.431 & 0.11 & 2.912 & 1.01 \\
\hline
\end{tabular}

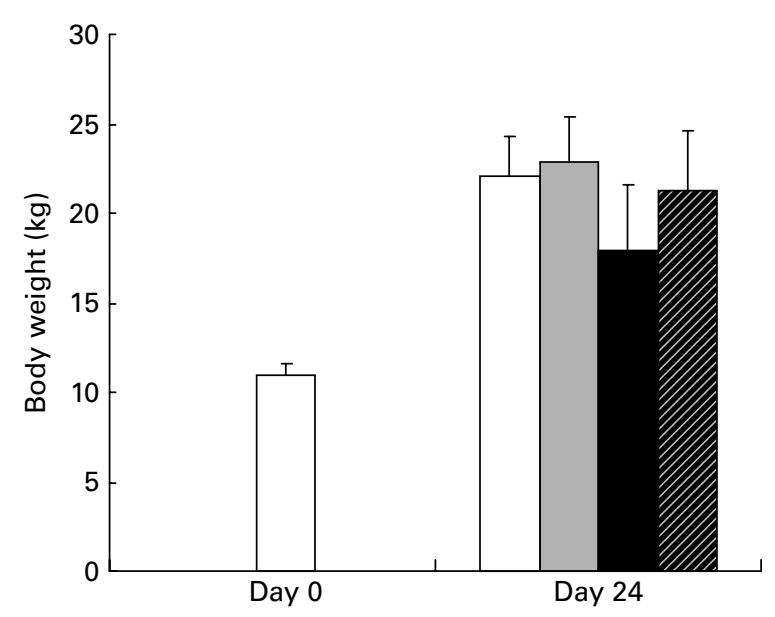

Fig. 1. Influence of dietary mycotoxins and calcium fructoborate $(\mathrm{CFrB})$ additive on body weight. Pigs received the control diet $(\square)$, calcium fructoborate (CFrB) additive diet $(\square)$ or diet contaminated with Fusarium mycotoxins ( $\square$ ) or Fusarium mycotoxins and CFrB additive $(\boldsymbol{Z})$. Animals were weighed at the end of the feeding trial $(24 \mathrm{~d})$. Values are means of body weight $(n 4)$, with standard errors represented by vertical bars. An ANOVA test was performed to compare the different groups. The table presents the performance (average daily weight gain (AWG) and feed:gain) obtained from pigs under the action of the four treatments. 
urea and glucose) in concentration with respect to the control diet. Compared with the control, the ingestion of the mycotoxin-contaminated feed had no effect on the total glucose, urea, $\mathrm{P}$ and alkaline phosphatase; however, it significantly increased the plasma concentration of total protein, $\mathrm{Na}$ and $\mathrm{Ca}(P<0 \cdot 05)$. Aspartate aminotransferase and alanine aminotransferase enzymes also increased, not significantly, from 37.9 (SEM 4.8) and 47.8 (SEM 9.8) $\mathrm{U} / 1$ in control groups to 41.8 (SEM 1.7 ) and 55.2 (SEM 1.9$) \mathrm{U} / 1$, respectively, in piglets feeding the contaminated diet, while bilirubin and chloride concentrations decreased (Table 3 ). The affected biochemistry parameters were partially attenuated by the addition of $\mathrm{CFrB}$ to the mycotoxin-contaminated diet.

\section{Plasma Ig concentration}

Table 4 shows that the concentration of the different plasma Ig subsets (IgA, IgG and IgM) ranged within the normal values for starter pigs, but the comparison between the control and Fusarium mycotoxin-contaminated diets resulted in $25.9 \%$ increase in IgG, and $29.8 \%$ in IgM level in the mycotoxin group at day 24 of the experiment. Feeding the diet supplemented with $\mathrm{CFrB}$ increased the concentration of IgM and IgG by 29.8 and $25.9 \%$, suggesting that the fructoborate compound per se stimulates the Ig synthesis, though it was not able to prevent the increased plasma Ig level in pigs that consumed the diet containing the contaminated maize which remained higher $(P<0.05)$ than the control $(3.23$ (sem 0.6) and $10 \cdot 17$ (SEM 3.2) v. $2 \cdot 05$ (SEM 0.4) and 6.36 (SEM 2.5)). A slight decrease in plasma IgA level induced by DON, and reversing by the mitigating additive, was observed.

\section{Proliferation of peripheral blood mononuclear cells}

The $\left[\right.$ methyl- $\left.{ }^{3} \mathrm{H}\right]$ thymidine proliferation assay used to determine the ex vivo proliferation of the PBMC derived from pigs fed with experimental treatments for $24 \mathrm{~d}$, and cultured for $72 \mathrm{~h}$ at $37^{\circ} \mathrm{C}$ and $5 \% \mathrm{CO}_{2}$, showed a significant effect of the Fusarium-contaminated diet on cell proliferation, which dramatically increased by $111.7 \%$ in pigs fed this treatment in comparison with control pigs $(P<0 \cdot 05)$. By contrast, the proliferation of the PBMC derived from pigs receiving the contaminated diet and supplemented with mitigating CFrB compound did not exceed the control level $(P<0 \cdot 05)$. The effect of treatments on PBMC proliferation was similar when the cells were stimulated in vitro with concanavalin A (Fig. 2). In order to verify that the increased PBMC proliferation was associated with an increased cell number, the trypan blue exclusion experiment was performed. We observed that the cell number increased from $7.9(\operatorname{SEM~} 1.2) \times 10^{6}$ cells $/ \mathrm{ml}$ in control PBMC to $15.9(\operatorname{sem} 3.9) \times 10^{6}$ cells $/ \mathrm{ml}$ in cells derived from mycotoxin-treated pigs $(P<0.05)$, and to $14.5($ SEM 1.0$) \times 10^{6}$ cells $/ \mathrm{ml}$ in cells of pigs fed with the contaminated diet and the CFrB supplement $(P<0 \cdot 05)$. Interestingly, even the number of these cells is higher than that of the control, and they are less reactive, with the [methyl- $\left.{ }^{3} \mathrm{H}\right]$ thymidine incorporation assay showing a decreased capacity to proliferate.

\section{Immune phenotyping of peripheral T-lymphocytes}

The effect of Fusarium toxins on T-lymphocyte subsets defined by the expression of $\mathrm{CD}^{+}, \mathrm{CD}^{+} \mathrm{CD}^{+}$and $\mathrm{CD}^{+} \mathrm{CD}^{+}$was measured by flow cytometry with fluorescently labelled antiCD4 and anti-CD8 antibodies (Fig. 3). The results indicated the capacity of the diet containing the contaminated maize, and especially of that containing the mitigating additive, to increase the percentage of peripheral $\mathrm{T}, \mathrm{CD} 3^{+}, \mathrm{CD}^{+} \mathrm{CD} 4^{+}$ and $\mathrm{CD}^{+} \mathrm{CD}^{+}$subsets of treated pigs in comparison with the control; while the increase induced by the mycotoxin diet was not significant, that produced by the fructoborate additive was significant $(P<0 \cdot 05)$. The addition of the organic additive to the contaminated feed determined a cumulative effect on the percentage of $\mathrm{CD}^{+}(P<0.05)$ and $\mathrm{CD}^{+} \mathrm{CD}^{+}(P<0.05)$ lymphocyte subsets, which increased to $133 \cdot 25$ and $142 \cdot 70 \%$ in comparison with the control.

\section{Respiratory burst of granulocytes}

To assess the effect of mycotoxins on the innate immune response, the intracellular production of $\mathrm{H}_{2} \mathrm{O}_{2}$, which was induced ex vivo by opsonised E. coli, was evaluated by flow cytometry in peripheral granulocytes derived from different diet groups (Fig. 4). Mycotoxin-contaminated feed increased the percentage of responsive cells in both unstimulated (15.4 v. $5 \cdot 1 \%$ in control), and, especially, under stimulated conditions $(70.95$ v. $22.65 \%$ for the control). The diet containing the CFrB additive seemed to normalise the exacerbated cellular immune response induced by Fusarium toxins (decreased by $42.6 \%, P<0 \cdot 05)$.

Table 2. Effect of Fusarium mycotoxins (M) and calcium fructoborate (CFrB) additive on organ weight* (Mean values with their standard errors, $n 4$ )

\begin{tabular}{|c|c|c|c|c|c|c|c|c|}
\hline \multirow[b]{3}{*}{ Organs (g) } & \multicolumn{8}{|c|}{ Treatments } \\
\hline & \multicolumn{2}{|c|}{$\mathrm{M}-\mathrm{CFrB}-$} & \multicolumn{2}{|c|}{$\mathrm{M}-\mathrm{CFrB}+$} & \multicolumn{2}{|c|}{$\mathrm{M}+\mathrm{CFrB}-$} & \multicolumn{2}{|c|}{$\mathrm{M}+\mathrm{CFrB}+$} \\
\hline & Mean & SEM & Mean & SEM & Mean & SEM & Mean & SEM \\
\hline Liver & $655 \cdot 0$ & $30 \cdot 1$ & $573 \cdot 3$ & $27 \cdot 4$ & $481 \cdot 7$ & 76.9 & $555 \cdot 0$ & $44 \cdot 4$ \\
\hline Kidney & $103 \cdot 3$ & $13 \cdot 3$ & $100 \cdot 0$ & $15 \cdot 3$ & 95.0 & $12 \cdot 6$ & $81 \cdot 7$ & $21 \cdot 3$ \\
\hline Spleen & $46 \cdot 7$ & $4 \cdot 4$ & $45 \cdot 0$ & $5 \cdot 8$ & $35 \cdot 0$ & $5 \cdot 8$ & $46 \cdot 7$ & $10 \cdot 9$ \\
\hline Lung & $251 \cdot 7$ & $6 \cdot 7$ & $248 \cdot 3$ & $13 \cdot 6$ & $196 \cdot 7$ & $24 \cdot 2$ & 308.3† & $29 \cdot 1$ \\
\hline
\end{tabular}


Table 3. Effect of dietary Fusarium mycotoxins (M) and calcium fructoborate (CFrB) additive administration on selected blood biochemical parameters in piglets*

(Mean values with their standard errors, $n 4$ )

\begin{tabular}{|c|c|c|c|c|c|c|c|c|}
\hline \multirow[b]{3}{*}{ Biochemical parameters } & \multicolumn{8}{|c|}{ Treatments } \\
\hline & \multicolumn{2}{|c|}{$\mathrm{M}-\mathrm{CFrB}-$} & \multicolumn{2}{|c|}{$\mathrm{M}-\mathrm{CFrB}+$} & \multicolumn{2}{|c|}{$\mathrm{M}+\mathrm{CFrB}-$} & \multicolumn{2}{|c|}{$\mathrm{M}+\mathrm{CFrB}+$} \\
\hline & Mean & SEM & Mean & SEM & Mean & SEM & Mean & SEM \\
\hline $\mathrm{Na}(\mathrm{mg} / \mathrm{l})$ & $1395^{b}$ & 20 & $1930^{\mathrm{a}}$ & 196 & $2097^{\mathrm{a}}$ & 134 & $2290^{\mathrm{a}}$ & 139 \\
\hline $\mathrm{Cl}(\mathrm{mg} / \mathrm{l})$ & 1100 & 16 & 745 & 159 & 873 & 104 & 990 & 86 \\
\hline $\mathrm{Ca}(\mathrm{mg} / \mathrm{l})$ & $103^{\mathrm{b}}$ & 4 & $99^{\mathrm{b}}$ & 5 & $111^{\mathrm{a}}$ & 2 & $108^{a, b}$ & 3 \\
\hline $\mathrm{P}(\mathrm{mg} / \mathrm{l})$ & $93^{\mathrm{b}}$ & 1 & $102^{a, b}$ & 6 & $91^{\mathrm{b}}$ & 4 & $110^{\mathrm{a}}$ & 3 \\
\hline Total protein $(\mathrm{g} / \mathrm{l})$ & $51^{\mathrm{c}}$ & 2 & $50^{c}$ & 2 & $58^{\mathrm{b}}$ & 1 & $66^{a}$ & 3 \\
\hline Urea $(\mathrm{mg} / \mathrm{l})$ & $204^{\mathrm{a}, \mathrm{b}}$ & $4 \overline{3}$ & $150^{\mathrm{b}}$ & 16 & $283^{\mathrm{a}}$ & 29 & $155^{\mathrm{b}}$ & 4 \\
\hline Glucose (mg/l) & 935 & 29 & 895 & 149 & 960 & 61 & 825 & 69 \\
\hline Bilirubin (mg/l) & 0.6 & 0 & 0.6 & 0 & 0.4 & 0 & 0.8 & 0 \\
\hline Alkaline phosphatase (IU/I) & $149 \cdot 0$ & 30.6 & $144 \cdot 0$ & 8.9 & $140 \cdot 0$ & $9 \cdot 8$ & 137.5 & $5 \cdot 3$ \\
\hline Aspartate aminotransferase (IU/I) & 47.8 & 9.8 & 57.4 & 1.6 & $55 \cdot 2$ & 1.9 & $63 \cdot 0$ & 0.1 \\
\hline Alanine aminotransferase (IU/I) & 37.9 & 4.8 & $47 \cdot 8$ & $1 \cdot 3$ & $41 \cdot 8$ & $1 \cdot 7$ & 38.2 & $7 \cdot 7$ \\
\hline
\end{tabular}

${ }_{a, b, c}$ Mean values within a row with unlike superscript letters were significantly different $(P<0.05)$.

* At the end of the experiment, plasma from the piglets was used to measure the blood biochemical parameters. ANOVA tests were performed to analyse the effect of different treatments on biochemical parameters.

\section{Liver cytokine synthesis}

As expected, the synthesis of IL- $1 \beta$, TNF- $\alpha$ and IL- 8 was revealed by ELISA measurement in the liver of pigs, but this cytokine production was altered in samples from animals which ingested the mycotoxins. As already observed for other immune parameters, the exposure to Fusarium mycotoxins for $24 \mathrm{~d}$ increased the synthesis of IL- $1 \beta$, TNF- $\alpha$ and IL- 8 by $123 \cdot 8,217 \cdot 1$ and $255 \cdot 1 \%$, respectively; the increase was significant for IL- 8 and TNF- $\alpha$ in comparison with the control group $(\mathrm{M}-\mathrm{CFrB}-)$ and the mitigating additive group $(\mathrm{M}-\mathrm{CFrB}+)(P<0.05)$. In contrast, the ingestion of the toxin associated with the fructoborate supplement significantly decreased $(P<0.05)$ the synthesis of the investigated cytokines (Fig. 5).

\section{Discussion}

Feed consumption is the first zootechnical parameter affected by Fusarium mycotoxins, which decrease, for example for DON, from a level $>1 \mathrm{ppm}$ in the feed of pigs ${ }^{(24,25)}$. A direct consequence of the reduced feed intake is the alteration of pig growth rate ${ }^{(26-28)}$. Indeed, in the present study, we demonstrated that the growth rate of pigs fed with a diet contaminated with Fusarium mycotoxin, mostly DON, decreased by $36 \cdot 2 \%$ compared with the controls over $24 \mathrm{~d}$, and feed efficiency increased by $30.98 \%$, confirming that the alteration of feed consumption represents the main effect of fusariotoxins on pigs. The lowered performance induced by Fusarium toxins was alleviated in pigs of the $\mathrm{M}+\mathrm{CFrB}+$ group following the supplementation with the fructose and the boron compound. Our results are in agreement with those of Armstrong et $a{ }^{(29)}$ and Armstrong \& Spears ${ }^{(30)}$, who also observed an increase in average daily weight gain and feed intake in pigs that consumed boron-supplemented diets following an intramuscular injection of lipopolysaccharide. Other studies testing the efficacy of polysaccharide products have shown either a beneficial or no effect for counteracting Fusarium toxins. Dried apple pomace (a by-product of apple juice production rich in pectin and other NSP) incorporated at the level of $8 \%$ in a Fusarium mycotoxin-contaminated feed $(3100 \mathrm{ppb}$ DON and $65 \mathrm{ppb}$ ZEA) was able to restore the growth rate of weaner piglets ${ }^{(31)}$, while polymeric glucomannan (0.05, $0 \cdot 1,0 \cdot 2$ and $1 \%$ in feed) had no beneficial effect on the zootechnical performance of growing pigs fed with a Fusarium

Table 4. Immunological values in pigs fed diets contaminated with Fusarium mycotoxins (M) and calcium fructoborate (CFrB) additive*

(Mean values with their standard errors, $n 4$ )

\begin{tabular}{|c|c|c|c|c|c|c|c|c|}
\hline & \multicolumn{8}{|c|}{ Treatments } \\
\hline & \multicolumn{2}{|c|}{$\mathrm{M}-\mathrm{CFrB}-$} & \multicolumn{2}{|c|}{$\mathrm{M}-\mathrm{CFrB}+$} & \multicolumn{2}{|c|}{$\mathrm{M}+\mathrm{CFrB}-$} & \multicolumn{2}{|c|}{$\mathrm{M}+\mathrm{CFrB}+$} \\
\hline & Mean & SEM & Mean & SEM & Mean & SEM & Mean & SEM \\
\hline $\operatorname{lgA}(\mathrm{mg} / \mathrm{ml})$ & 0.77 & 0.1 & 0.71 & $0 \cdot 1$ & 0.63 & $0 \cdot 0$ & 0.74 & 0.0 \\
\hline $\mathrm{lgM}(\mathrm{mg} / \mathrm{ml})$ & $2.05^{\mathrm{b}}$ & 0.3 & $2 \cdot 66^{a, b}$ & 0.1 & $2 \cdot 43^{\mathrm{b}, \mathrm{c}}$ & 0.1 & $3.23^{a}$ & 0.3 \\
\hline $\lg G(\mathrm{mg} / \mathrm{ml})$ & $6 \cdot 36^{b}$ & 1.5 & $8 \cdot 01^{a, b}$ & 1.0 & $7 \cdot 81^{a, b}$ & 1.0 & $10 \cdot 17^{a}$ & 1.9 \\
\hline
\end{tabular}

a,b,c Mean values within a row with unlike superscript letters were significantly different $(P<0.05)$.

* At the end of the experiment, blood samples were collected, and the total concentration of Ig subsets from plasma was measured by ELISA after plasma dilution: 1:4000 (IgA), 1:6000 (IgM) and 1:60000 (IgG). Results are expressed as IgA, IgM or IgG content in the plasma of piglets. ANOVA tests were performed to analyse the effect of treatment on Ig levels. 


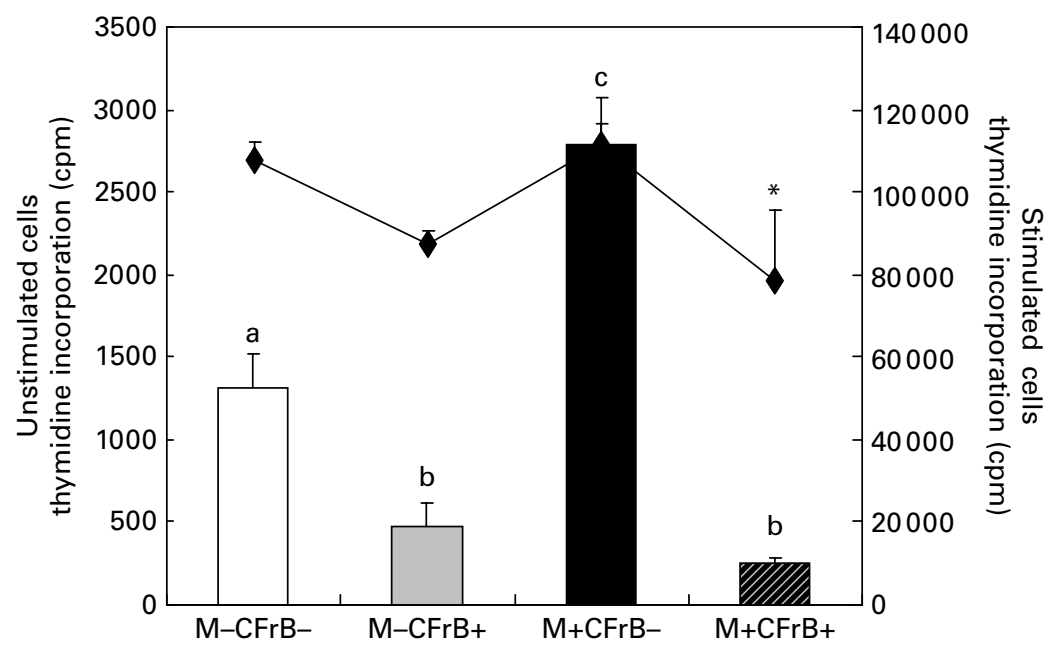

Fig. 2. Effect of dietary mycotoxins $(M)$ and calcium fructoborate $(\mathrm{CFrB})$ additive on ex vivo porcine peripheral blood mononuclear cell (PBMC) proliferation. PBMC derived from pigs receiving the control diet $(\square)$, CFrB-additive diet $(\square)$ or diet contaminated with Fusarium mycotoxins ( $\square$ ) or Fusarium mycotoxins plus CFrB additive ( $(\boldsymbol{a})$ were stimulated or unstimulated with concanavalin $\mathrm{A}(\mathrm{ConA}, 10 \mu \mathrm{g} / \mathrm{ml})$ and cultured $\left(1 \times 10^{6} \mathrm{cells} / \mathrm{ml}\right)$ for $72 \mathrm{~h}$ at $37^{\circ} \mathrm{C}$ and $5 \% \mathrm{CO}_{2}$. The ex vivo proliferation of PBMC was measured by the [methyl- $\left.{ }^{3} \mathrm{H}\right]$ thymidine incorporation assay, and the results are expressed as counts/min $(\mathrm{cpm})$. Values are means, with standard errors represented by vertical bars $(n 4)$. ANOVA tests were performed to compare PBMC proliferation in control and treated animals; ${ }^{\text {a,b,c }}$ Mean values with unlike letters were significantly different between the control and treated animals for proliferation under the basal condition $(P<0.05)$. ${ }^{*}$ Mean values were significantly different between the contaminated diet and contaminated diet plus CFrB additive under the ConA-stimulated condition $(P<0.05)$.

mycotoxin-contaminated diet (mainly DON) ${ }^{(26,32)}$. However, in these studies, the level of mycotoxin was higher than that reported in the present study ( 5.5 and $2-2.5 \mathrm{ppm}$, respectively).

The supplementation of the $\mathrm{CFrB}$ compound to the diet containing contaminated maize counteracted organ-weight alterations in the present study, but it had no beneficial effect on the biochemistry parameters modified by mycotoxin. The inability of $0 \cdot 1$ and $0 \cdot 2 \%$ of dietary glucomannan polymer

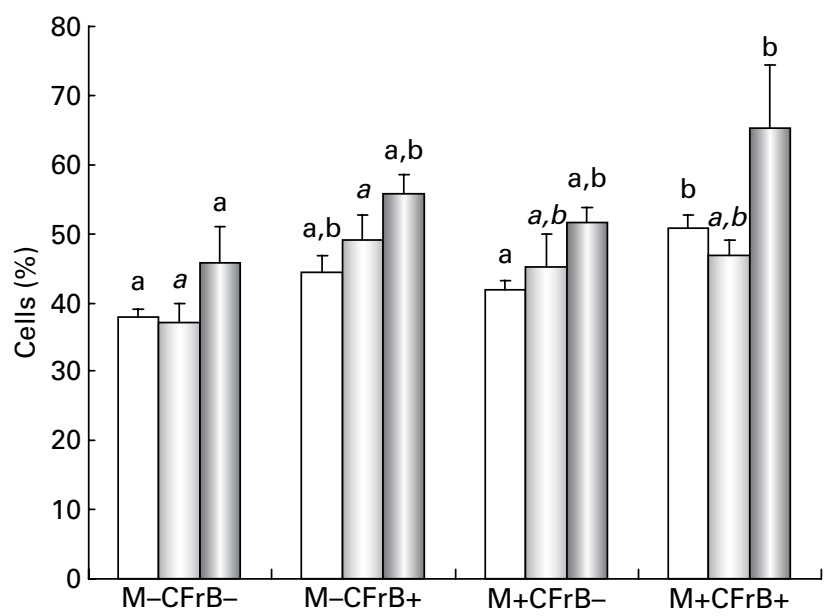

Fig. 3. Flow cytometric identification of $\mathrm{CD}^{+}(\square), \mathrm{CD}^{+} \mathrm{CD}^{+}(\square)$ and $\mathrm{CD}^{+} \mathrm{CD}^{+}(\square)$ blood T-lymphocytes following treatments with Fusarium mycotoxins $(\mathrm{M})$ and calcium fructoborate (CFrB) additive. Blood samples taken after $24 \mathrm{~d}$ from pigs fed the $\mathrm{M}-\mathrm{CFrB}-$ diet, $\mathrm{M}-\mathrm{CFrB}+$ diet or $\mathrm{M}+\mathrm{CFrB}-$ diet and $\mathrm{M}+\mathrm{CFrB}+$ diet were stained for CD3 $\varepsilon, \mathrm{CD} 4 a$ and CD8a subsets, and analysed by flow cytometry. Values are means, representing the average of the percentage of $\mathrm{CD}^{+}, \mathrm{CD}^{+} \mathrm{CD}^{+}$and $\mathrm{CD} 3^{+} \mathrm{CD} 8^{+}$ blood T-lymphocytes at $24 \mathrm{~d}$ following treatments with Fusarium mycotoxins and CFrB additive, with their standard errors represented by vertical bars (n 4). ANOVA test was performed to compare the percentage of T-cell subsets between the control and treated animals. ${ }^{a, b}$ Mean values with unlike letters were significantly different between the treatments $(P<0.05)$. to prevent some of the Fusarium toxin-induced alterations in serum chemistry, but to restore the significant reduction of liver weight in pigs, was also reported by Swamy et al. ${ }^{(26)}$. Nevertheless, these authors observed that the same concentrations of glucomannan polymer were more effective in reversing the alterations in haematology, serum chemistry and biliary IgA concentrations in broiler chickens ${ }^{(33)}$.

Similar to other mycotoxins, the presence of DON and other Fusarium toxins in animal feed could have serious consequences on their immune functions ${ }^{(34,35)}$. Many in vivo and in vitro studies have described the effects of trichothecenes on the cellular and humoral response, leading to the alteration of Ig and cytokine synthesis, decreased lymphocyte proliferation, etc. ${ }^{(35,36)}$. Of particular interest is the effect of DON on antibody synthesis, which seems to be related to the induction of certain cytokines such as IL-2, IL-5 and IL-6 at Payer's patch level $^{(3)}$. In pigs, the results are contradictory, showing either an increase in serum $\operatorname{Ig}^{(37-40)}$ or no effect in $\mathrm{Ig}$ levels $^{(41-44)}$. In our experiment, the feeding of contaminated diet to pigs significantly increased $(P<0.05)$ the plasma IgG and IgM concentrations, and did not influence the plasma IgA level (Table 4). The elevated IgM and IgG concentrations induced by Fusarium toxins in the present investigation are in accordance with the experiments conducted by Goyarts et $a{ }^{(38)}$, Swamy et $a l .{ }^{(26)}$ and Pinton et $a l^{(39)}$ with growing pigs fed with a higher concentration of DON (5.7, 5.5 and $2.5 \mathrm{ppm}$, respectively). A stimulative effect on the humoral and cellular immune response was also determined by CFrB alone (increased plasma IgG and IgM concentrations and increased percentage of $\mathrm{CD}^{+}$and $\mathrm{CD}^{+}$lymphocyte subsets), but the additive was not effective in preventing these increased parameters in pigs that consumed the Fusarium toxincontaminated diet (Table 4; Fig. 3). In contrast to the present results, the supplementation of Fusarium-contaminated feed 


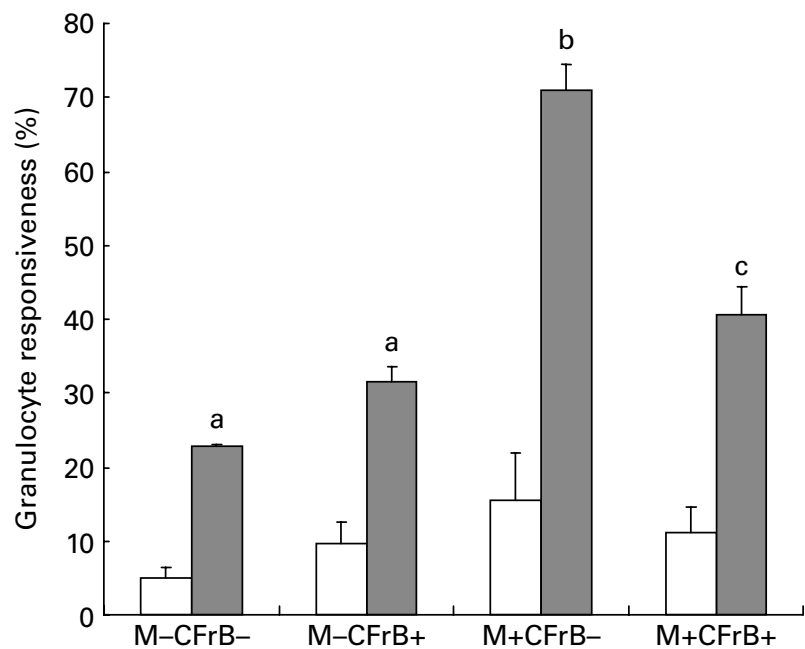

Fig. 4. Effect of dietary mycotoxins $(\mathrm{M})$ and calcium fructoborate (CFrB) additive on the respiratory burst of circulating granulocytes. Ice-cold heparinised blood $(100 \mu l)$ was activated with unlabelled opsonised Escherichia coli for $10 \mathrm{~min}$ at $37^{\circ} \mathrm{C}$. The intracellular production of $\mathrm{H}_{2} \mathrm{O}_{2}$ by peripheral granulocytes was performed by flow cytometry in the whole blood using the fluorogenic substrate dihydrorhodamine 123 and propidium iodide as the DNA-staining solution. Cell analysis was done by flow cytometry using CellQuest software (Becton Dickinson, San Diego, CA, USA). At least 10000 events were analysed. Data were expressed as the percentage of responsive cells under basal conditions (no stimulus, $\square$ ) or in response to a particular ex vivo stimulus (E. coli, $\square$ ), meaning the percentage of cells with fluorescence intensity above a defined threshold (M2). Values are means, with their standard errors represented by vertical bars $(n 4)$. ANOVA tests were performed to analyse the effect of different treatments on cytokine production. ${ }^{a, b, c}$ Mean values with unlike letters were significantly different between the treatments $(P<0.05)$.

with glucomannan was able to counteract the increased IgM and IgG concentrations in the experiment conducted by Swamy et al. ${ }^{(26)}$ and, partially, the increased percentage of $\mathrm{CD}^{+}$and $\mathrm{CD}^{+}$lymphocyte subsets in the trial conducted by Girish et al. ${ }^{(45)}$.

It has been shown that DON, a marker of Fusarium infestation, is able to increase the synthesis of IL-2, a cytokine with a key role in cell proliferation ${ }^{(26,44)}$; this fact along with the stimulation of ribotoxic stress and the activation of mitogenactivated protein kinases, enzymes which catalyse reactions in signal transduction related to proliferation, differentiation and apoptosis ${ }^{(3)}$, could explain the effect of Fusarium mycotoxins on lymphocyte proliferation observed in the present study and in other similar studies. Thus, a series of in vivo studies have already shown that the non-specific capacity of lymphocytes to proliferate is dramatically increased in the growing pigs receiving 1.6 and $3.6 \mathrm{ppm} \mathrm{DON}^{(46,47)}$. In poultry ${ }^{(45)}$, increased proliferation was observed in the crypt and the villi of the small intestine when birds ingested diets containing Fusarium toxins (diacetoxyscirpenol or T-2 toxins). Data from the present trial showed that the oral administration of $1790 \mathrm{ppb}$ DON and less amount of ZEA, fumonisin and HT-2 toxins for $24 \mathrm{~d}$ resulted in a significantly higher ex vivo proliferation response of peripheral blood lymphocytes to a mitogen stimulation or under basal conditions $(P<0 \cdot 05)$.

Dietary fructoborate supplementation was very effective in reversing the alteration of $\mathrm{PBMC}$ proliferation, as well as in the respiratory burst of circulating granulocytes, and in the production of liver pro-inflammatory cytokines, which are important aspects of the immune response modified under the mycotoxin action in the present trial. In vitro studies of Scorei et al. ${ }^{(48,49)}$ have highlighted the anti-inflammatory and antioxidant properties of fructoborate, showing that the addition of $0 \cdot 2-1 \mathrm{~mm}-\mathrm{CFrB}$ to cultured RAW 264.7 macrophages reduced the secretion of IL-6, IL-1 $\beta$ and NO by lipopolysaccharide-stimulated cells in a dose-dependent manner, and markedly diminished the intracellular reactive oxygen species in keratinocytes. These authors have supported the hypothesis that the soluble carbohydrate compounds of boron formed by the combination of boric acid with free glucides, glycolipids and glycoproteins buffer the reactive species of oxygen by developing organic peroxyborates. Other authors $^{(50-52)}$ have also suggested that boron decreased the production of $\mathrm{H}_{2} \mathrm{O}_{2}$ generated during the respiratory burst by the up-regulating activity of some enzymes (superoxide dismutase and glutathione peroxidase) involved in the respiratory burst cascade. In our feeding experiment, dietary boron compound supplementation significantly decreased the synthesis of liver TNF- $\alpha$ and IL- 8 , and the exacerbated respiratory burst developed in the peripheral granulocytes.

To our knowledge, boron esters (fructoborate) or other feeds containing fructose have never been tested as possible antidotes to mycotoxins in pigs. We consider that its efficacy to alleviate the performance and some aspects of the immune response of pigs altered by Fusarium mycotoxins may derive from the specific and various properties of its components (proteins, boron and fructose), and from the mechanism that such a complex compound could start. It has been hypothesised that carbohydrates might trap the mycotoxin molecule, preventing toxin absorption, or might contribute

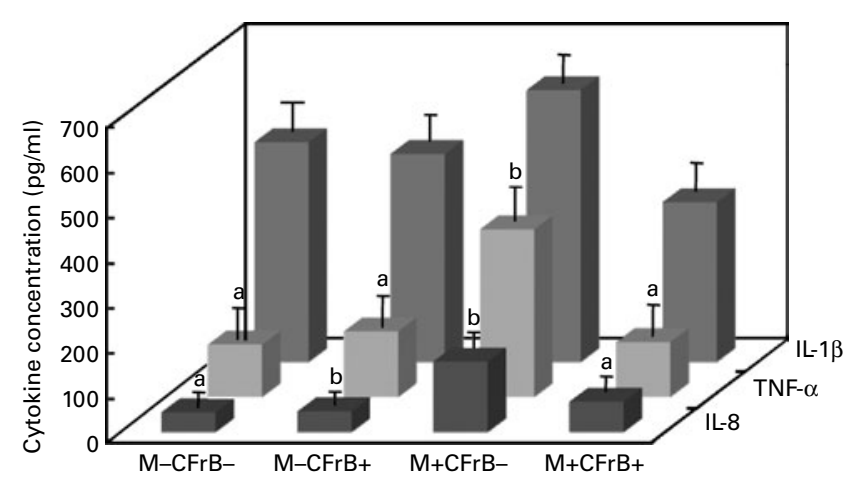

Fig. 5. Effect of dietary mycotoxins $(M)$ and calcium fructoborate $(\mathrm{CFrB})$ additive on the synthesis of cytokines, IL-8, TNF- $\alpha$ and IL-1 $\beta$, in the liver of pigs. Samples of the liver were weighed and homogenised in phosphate buffer containing $1 \%$ igepal, $0.5 \%$ sodium deoxycholate, $0.1 \%$ SDS and complete (EDTA-free) protease inhibitor cocktail tablets. The homogenates were kept for $30 \mathrm{~min}$ on ice and then centrifuged at $10000 \mathrm{~g}$ at $4^{\circ} \mathrm{C}$ for $10 \mathrm{~min}$. TNF- $\alpha$, IL- $1 \beta$ and IL- 8 concentrations in the supernatants were determined by ELISA using R\&D Systems kits (according to the manufacturer's instructions; R\&D Systems, Minneapolis, MN, USA). Optical densities were measured on an ELISA reader (Tecan, Sun Rise, Austria) at a wavelength of $450 \mathrm{~nm}$. Values are means, with their standard errors represented by vertical bars ( $n$ 4). ANOVA tests were performed to analyse the effect of different treatments on cytokine production. ${ }^{\mathrm{a}, \mathrm{b}}$ Mean values with unlike letters were significantly different between the treatments $(P<0.05)$. 
to the biodegradation of mycotoxins into non-toxic metabolites by the stimulation of intestinal microflora activity; at the intestine level, carbohydrates increase the amount of water in the gut lumen, protein synthesis in small-intestinal mucosal cells and stimulate cell division ${ }^{(31)}$. Boron provided support (as a cofactor) to important enzymes involved in the antioxidant processes, and demonstrated immunomodulatory function (anti-inflammatory and Ig-stimulant), which enhanced the resistance of animals to mycotoxin. Boron is also implicated in $\mathrm{Ca}$ metabolism, and these two elements affect similar systems including cell membrane characteristics, trans-membrane signalling, etc. ${ }^{(53)}$. Although we can conclude that the addition of complex compounds to animal feed provides versatile tools to prevent mycotoxicosis, the present study has to be completed with further research aiming to establish whether fructoborate additive remains efficient against a higher dose of mycotoxin under mycotoxin co-contamination conditions. Different dietary rates of fructoborate additive are required in order to study in more detail the health-promoting effects.

\section{Acknowledgements}

The present study was supported by funds from the National Research Project 'CEEX 25' 2005-08 and 'PNII' 2008-11 granted by the Romanian Ministry of Research and Technology. The authors would like to thank Dr Romulus Scorei for providing the $\mathrm{CFrB}$ additive and technical information. Thanks are also due to Dr Olga Starodub for her help with the English text. I. T. conducted and designed the research and wrote the manuscript. D. E. M. contributed to the manuscript preparation and, along with M. M. performed biochemistry, Ig and cytokine determinations and analysed the data. G. M. and I. N. performed thymidine proliferation assay, flow-cytometry experiments and analysed the data. C. T. and M. S. contributed to the progress of the in vivo experiment (animal performance, sample collection and preparation). M. O. analysed the chemical composition of the feed used in the trial. All authors read and approved the final manuscript.

\section{References}

1. Smith TK, McMillan EG \& Castillo JB (1997) Effect of feeding blends of Fusarium mycotoxin-contaminated grains containing deoxynivalenol and fusaric acid on growth and feed consumption of immature swine. J Anim Sci 75, 2184-2191.

2. Agence Francaise de Securite Alimentaire - AFSA (2009) Report: Evaluation des risques liés à la présence de mycotoxines dans la chaîne alimentaire (Report: Assessment of Risk Associated with the Presence of Mycotoxins in the Food Chain). http://www.afssa.fr/index.htm.

3. Pestka JJ \& Smolinski AT (2005) Deoxynivalenol: toxicology and potential effects on humans. J Toxicol Environ Health B Crit Rev 8, 39-69.

4. Lillehoj EB (1983) Effect of environmental and cultural factors on aflatoxin contamination of developing corn kernels. In Aflatoxins and Aspergillus flavus in Corn, pp. 27-34 [UL Diener, RL Asquith and JW Dickens, editors]. Aubum University. Southern Cooperative Series Bulletin 279. Auburn, AL: Alabama Agricultural Experiment Station.
5. Bhatnagar D, Lillehoj EB, Bennett JW, et al. (1991) Biological detoxification of mycotoxins. In Mycotoxin and Animal Food, Chapter 36, pp. 815-826. Boca Raton, FL: CRC Press.

6. Kabak B, Dobson ADW \& Işl V (2006) Strategies to prevent mycotoxin contamination of food and animal feed: a review. Crit Rev Food Sci Nutr 46, 593-619.

7. Bata A \& Lasztity R (1999) Detoxification of mycotoxin-contaminated food and feed by microorganisms. Trends Food Sci Technol 10, 223-228.

8. Karlovsky P (1999) Biological detoxification of fungal toxins and its use in plant breeding, feet, and food production. Nat Toxins 7, 1-23.

9. Avantaggiato G, Havenaar R \& Visconti A (2007) Assessment of the multi-mycotoxin-binding efficacy of a carbon/aluminosilicate-based product in an in vitro gastrointestinal model. J Agric Food Chem 55, 4810-4819.

10. Bata A \& Lasztity R (1999) Detoxification of mycotoxin-contaminated food and feed by microorganisms. Trends Food Sci Technol 10, 223-228.

11. Döll S, Gericke S, Dänicke S, et al. (2005) The efficacy of a modified aluminosilicate as a detoxifying agent in Fusarium toxin contaminated maize containing diets for piglets. $J$ Anim Physiol Anim Nutr 89, 342-358.

12. The European Food Safety Authority (EFSA) Journal (2009) Review of Mycotoxin-detoxifying Agents used as Feed Additives: Mode of Action, Efficacy and Feed/food Safety. Scientific Report Q-2009-00839. http://www.efsa.europa.eu/en/ scdocs/scdoc/22e.htm

13. The European Food Safety Authority (EFSA) Journal (2005) Opinion of the Scientific Panel on Additives and Products or Substances Used in Animal Feed on a Request from the Commission on the Safety of the Product "Biomin BBSH 797" for Piglets, Pigs for Fattening and Chickens for Fattening. http://www.efsa.europa.eu

14. Galvano F, Piva A, Ritieni A, et al. (2001) Dietary strategies to counteract the effects of mycotoxins: a review. J Food Prot 64, 120-131.

15. Pié S, Lallès JP, Blazy F, et al. (2004) Weaning is associated with an upregulation of expression of inflammatory cytokines in the intestine of piglets. J Nutr 134, 641-647.

16. EC/576 (2006) European Commission recommendation on the presence of deoxynivalenol, zearalenone, ochratoxin A, T-2 and HT-2 and fumonisins in products intended for animal feeding. Official J European Union I, 229/7-229/9.

17. Rotaru P, Scorei R, Harabor A, et al. (2010) Thermal analysis of a calcium fructoborate sample. Thermochim Acta 506, $8-13$.

18. The Romanian Standardized Association (ASRO) Standardized Bulletin (2010) SR ISO 6496/2001. http://www.asro.ro

19. The Romanian Standardized Association (ASRO) Standardized Bulletin (2010) SR EN ISO 5983-2/2009. http://www. asro.ro

20. The Romanian Standardized Association (ASRO) Standardized Bulletin (2010) SR ISO 6492/2001. http://www.asro.ro

21. The Romanian Standardized Association (ASRO) Standardized Bulletin (2010) SR EN ISO 6865/2002. http://www. asro.ro

22. The Romanian Standardized Association (ASRO) Standardized Bulletin (2010) SR EN ISO 2171/2010. http://www. asro.ro

23. Marin DE, Taranu I, Pascale F, et al. (2006) Sex-related differences in the immune response of weanling piglets exposed to low doses of fumonisin extract. Br J Nutr 95, 1-9.

24. Etienne M (2007) Effets biologiques et physiologiques d'une mycotoxine, le déoxynivalénol (DON), chez le porc (Biological and physiological effects of deoxynivalenol (DON), 
a mycotoxin, in the pig). Journées Rech Porcine 39, 407-418.

25. Grosjean F, Callu P, Pinton P, et al. (2003) Quantification des effets de la consommation de déoxynivalénol (DON) par le porcelet sevré (Quantification of the effects of deoxynivalenol consumption by weaned piglets). Journées Rech Porcine 35, 443-450.

26. Swamy HVLN, Smith TK, MacDonald EJ, et al. (2002) Effects of feeding a blend of grains naturally contaminated with mycotoxins Fusarium on swine performance, brain regional neurochemistry, and serum chemistry and the efficacy of a polymeric glucomannan mycotoxin adsorbent. J Anim Sci 80, 3257-3267.

27. Foster BC, Trenholm HL, Friend DW, et al. (1986) Evaluation of different sources of deoxynivalenol (vomitoxin) fed to swine. Can J Anim Sci 66, 1149-1154.

28. Friend DW, Trenholm HL, Elliot JI, et al. (1982) Effect of feeding vomitoxin-contaminated wheat to pigs. Can J Anim Sci 62, 1211-1222.

29. Armstrong TA, Flowers WL, Spears JW, et al. (2002) Longterm effects of boron supplementation on reproductive characterstics and bone mechanical properties in gilts. J Anim Sci 80, 154-161.

30. Armstrong TA \& Spears JW (2003) Effect of boron supplementation of pig diets on the production of tumor necrosis factor-alpha and interferon-gamma. J Anim Sci 81, 2552-2561.

31. Gutzwiller A, Czegledi L, Stoll P, et al. (2007) Effects of Fusarium toxins on growth, humoral immune response and internal organs in weaner pigs, and the efficacy of apple pomace as an antidote. J Anim Physiol Anim Nutr 91, 432-438.

32. Wetscherek W, Huber H \& Lew J (1998) Einsatz von mit Mycotoxinen kontaminiertern Mais und von Detoxifikationsmitteln in der Schweinemast (Use of corn contaminated with mycotoxins and detoxifying in pigs). Proc Soc Nutr Physiol 7, 93 .

33. Swamy HVLN, Smith TK, Cotter PF, et al. (2002) Effects of feeding blends of grains naturally contaminated with Fusarium mycotoxins on production and metabolism in broilers. Poult Sci 81, 966-975.

34. Oswald IP, Marin DE, Bouhet S, et al. (2005) Immunotoxicological risk of mycotoxins for domestic animals. Food Add Contam 22, 354-360.

35. Pestka JJ, Zhou HR, Moon Y, et al. (2004) Cellular and molecular mechanisms for immune modulation by deoxynivalenol and other trichothecenes: unravelling a paradox. Toxicol Lett 153, 61-73.

36. Meky FA, Hardie LJ, Evans SW, et al. (2001) Deoxynivalenolinduced immunomodulation of human lymphocyte proliferation and cytokine production. Food Chem Toxicol 39, 827-836.

37. Grosjean F, Pinton P, Callu P, et al. (2007) Effets de la consommation par le porcelet sevré d'aliment contenant du blé naturellement fusarié (Effects of consumption of diet including Fusarium naturally contaminated wheat in weaned piglets). Journees Rech. Porcine 39, 427-428.

38. Goyarts T, Danicke S, Tiemann U, et al. (2006) Effect of the Fusarium toxin deoxynivalenol (DON) on IgA, IgM and IgG concentrations and proliferation of porcine blood lymphocytes. Toxicol In vitro 20, 858-867.

39. Pinton P, Accensi F \& Beauchamp E (2006) Effets de la consommation d'aliment naturellement contaminé par du déoxynivalénol (DON) sur la réponse vaccinale du porc (Effects of consumption of naturally contaminated feed by deoxynivalenol (DON) on the vaccinal immune response in pigs). Journées Rech Porcine 38, 399-406.

40. Rotter BA, Prelusky DB \& Pestka JJ (1996) Toxicology of deoxynivalenol (vomitoxin). J Toxicol Environ Health 48, $1-34$.

41. Accensi F, Pinton P, Callu P, et al. (2006) Ingestion of low doses of deoxynivalenol does not affect haematological, biochemical, or immune responses of piglets. J Anim Sci $\mathbf{8 4}$, 1935-1942.

42. Danicke S, Valenta H, Klobasa F, et al. (2004) Effects of graded levels of Fusarium toxin contaminated wheat in diets for fattening pigs on growth performance, nutrient digestibility, deoxynivalenol balance and clinical serum characteristics. Arch Anim Nutr 58, 1-17.

43. Doll S, Danicke S, Ueberschar KH, et al. (2003) Effects of graded levels of Fusarium toxin contaminated maize in diets for female weaned piglets. Arch Anim Nutr 57, $311-334$

44. Swamy HVLN, Smith TK, MacDonald EJ, et al. (2003) Effects of feeding a blend of grains naturally contamined with Fusarium mycotoxins on growth and immunological measurements of starter pigs, and the efficacy of a polymeric glucomannan mycotoxin adsorbent. J Anim Sci 81, $2792-2803$.

45. Girish CK, Smith TK, Boermans HJ, et al. (2010) Effects of dietary Fusarium mycotoxins on intestinal lymphocyte subset populations, cell proliferation and histological changes in avian lymphoid organs. Food Chem Toxicol $\mathbf{4 8}$, 3000-3007.

46. Pinton P, Royer E, Accensi F, et al. (2004) Effets zootechniques et immunitaires de la consommation d'aliment naturellement contaminé par du déoxynivalénol (DON) chez le porc en phase de croissance ou de finition (Effects of feeding growing or finishing pigs with deoxynivalenol (DON) natually contaminated feed on growth performance and immunological status). Journées Rech Porcine 36, 301-308

47. Grosjean F, Taranu I, Skiba F, et al. (2002) Comparaisons de blés fusariés naturellement à des blés sains, dans l'alimentation du porcelet sevré (Comparisons of different naturally Fusarium-contaminated wheats with uncontaminated wheats in weaned piglet diets). Journées Rech Porcine 34, 333-339.

48. Scorei RI, Ciofrangeanu C, Ion R, et al. (2010) In vitro effects of calcium fructoborate upon production of inflammatory mediators by LPS-stimulated RAW 264.7 macrophages. Biol Trace Elem Res 135, 334-344.

49. Scorei R, Cimpoiasu VM \& Iordachescu D (2005) In vitro evaluation of the antioxidant activity of calcium fructoborate. Biol Trace Elem Res 107, 127-134.

50. Luo D \& Eckhert CD (2000) Boron responsive human genes. FASEB J 14, A478.

51. Hunt CD \& Idso JP (1999) Dietary boron as physiological regulator of the normal inflammatory response: a review and current reaserch progress. J Trace Elem Exo Med 12, 221-223.

52. Nielsen FH (1997) Boron in human and animal nutrition Plant Soil 193, 199-208.

53. Nielsen FH (1994) Biochemical and physiologic consequences of boron deprivation in humans. Environ Health Perspect 102, Suppl. 7, 59-63. 